\title{
ANALYSIS ON THE POSE AND DYNAMIC RESPONSE OF HYDRAULIC SUPPORT UNDER DUAL IMPACT LOADS
}

\author{
Zeng, X. T. ${ }^{* * *}$; Meng, G. Y., ${ }^{* \#} \&$ Zhou, J. H. ${ }^{* * *}$ \\ *School of Mechanical, Electronic and Information Engineering, China University of Mining and \\ Technology (Beijing), Beijing 100083, China \\ *** Test Center of China Coal Research Institute, Beijing 100013, China \\ **** Department of Computer Science and Engineering, University of Oulu, FI-90014 Oulu, Finland \\ E-Mail: mgy@ cumtb.edu.cn ( ${ }^{*}$ Corresponding author)
}

\begin{abstract}
Hydraulic support is significant in the mining process because it serves as the primary supporting equipment in a coal mine. The roof beam and shield beam of hydraulic support are easily damaged because of the dynamic impact loads it has to bear. To improve its working performance, this study investigated the movement trend, pose, and mechanical response of hydraulic support when its roof beam and shield beam were subjected to impact loads. First, the roof beam, shield beam, and bars were made flexible using Hypermesh software. Then, a numerical simulation model of the hydraulic support was constructed using Adams software. The working resistance of the support was provided by two active external load signals applied vertically to the roof beam and located above the upper column. The impact load was applied along the normal direction of the top beam and the shield beam toward the symmetrical centre. The pose and stress state variations of the support were obtained under different impact conditions through measuring the variations of the rotation angles of the roof beam, deflection angles of the columns, length of the columns and balanced jack, and force of the hinge points. Results indicate that various trends of the hydraulic support under different impact effects are different, and in general, the support is more easily damaged when the impact load acts both on the roof beam and the shield beam compared with the single impact condition. This study is helpful for the stability control and structural design of the hydraulic support.

(Received in June 2017, accepted in November 2017. This paper was with the authors 2 months for 1 revision.)
\end{abstract}

Key Words: Hydraulic Support, Dynamic Response, Impact Load, Pose Analysis

\section{INTRODUCTION}

The hydraulic support is the main supporting equipment for underground mining [1]. During the mining process, this support helps push the armoured face conveyor, advance itself, and support the roof of the stope. Therefore, it prevents the roof from falling and maintains a safe operating space. The reliability of the hydraulic support is one of the key factors that determine a safe and efficient production of a coal mining face.

The load-bearing state of a hydraulic support is determined by the interaction effects between the support and the roof. Its load capacity varies with the changes in geological conditions and actual working conditions [2, 3]. Moreover, the appearance of pressure in the coal mining face, operating pose of the support, and interaction between roof and support play important roles in mining [4-6], and the properties of the roof (soft or hard) can affect its integrity and settling speed. The actual loading state and operating height of the support are also affected [7, 8]. Among all the factors that influence the working state of the support, impact load is a key factor that causes damage to the support [9-11]. Therefore, a detailed study on the dynamic response of the hydraulic support under impact load helps provide a basis for the structural design and adaptive control of hydraulic support. 


\section{STATE OF THE ART}

The impact problem of hydraulic support is characterized by high requirements for its roof beam and shield beam. However, contemporary research mainly focuses on the mechanism of the impact load and the static strength analysis, among other aspects. Few studies on the impact resistance of hydraulic support are related. For instance, Singh and Singh put forward a numerical simulation method for predicting the occurrence time of the impact load [12]. However, no analysis has been conducted on the impact load on hydraulic support. Oblak et al. proposed a method based on mathematical modelling, which could be used to determine the optimum value of the structural parameters of a hydraulic support [13]. The method aimed to ensure the minimum lateral displacement of the support to meet its motion requirements. Wang et al. carried out an in-depth investigation on the coupling relationship between the roof and the support [14]. They summarized the relationship into three aspects, namely, strength, stiffness, and stability coupling. In particular, they studied the large mining height hydraulic support. The key technologies for strata control in the large mining height face were proposed as follows: determination of support capacity, coal wall spalling control, coupling control of the stiffness, and stability between support and roof. However, most of the above analyses were focused on the level of static analysis. Wang et al. conducted stress and buckling stability analyses on hydraulic support with double sleeve legs [15]. The safety factors for parts of the legs were obtained, and relevant evaluations were carried out based on the standard. Ren determined the reasonable height of the support via a force analysis of the shield beam and equilibrium jack [16]. Furthermore, he conducted strength analysis of the roof beam under the torsional working condition and proposed an effective measure to improve the structure of the shield beam. Zhao et al. utilized a finite element simulation method to conduct a fatigue analysis of the welded structures of a hydraulic support and provided a theoretical reference for the fatigue design of the support [17]. Liang et al. studied the force transmission relationships of hinge points when an impact load is applied to the roof beam and determined that hinge points are different in sensitivity to the impact force [18]. The dynamic load-bearing characteristics and adaptability of the hydraulic support in the fully mechanized caving face with large mining height were obtained through Yu's theory analysis [19].

Given that hydraulic cylinders are the main operating unit in a hydraulic system, some scholars used the cylinder as the research object. Xuan et al. established the dynamic model of hydraulic cylinders and analysed their friction behaviours. The friction characteristics of the hydraulic cylinders with various sizes and materials were obtained under different external loads [20]. Boaventura et al. designed a hydraulic quadruped robot with a leg made of hydraulic cylinders. The static and dynamic movements were attained by a torque-controlled hydraulic actuation system [21]. Wang et al. investigated influences of nonlinear spring and frictional force on the dynamic properties of a moving hydraulic cylinder and found that soft or hard spring properties varied with different working conditions [22]. Jiang et al. derived the mathematical model of dynamic characteristic in a cylinder-controlled hydraulic system. Simulations were performed using SIMULINK module in MATLAB, and the cylinder's dynamic properties were obtained [23]. These studies were significant to obtaining the dynamic properties of a hydraulic system from the aspect of hydraulic cylinders, but the relations between the cylinder and the entire system were ignored. Hence, they could not reflect the real dynamic properties of a hydraulic system.

On the basis of the findings by these scholars, a certain type of large mining height support is used as an example to study the movement trend and pose of the support, force response of the hinge points, and vibration response of the column and balanced jack during the working process. Then, the numerical simulation method is used to simulate the double 
impact of the hydraulic support. Finally, the related analysis and discussion are conducted and discussed.

The remainder of this study is organized as follows. Section 3 establishes the numerical simulation model of the hydraulic support and determines the spring stiffness and the active impact load. Section 4 discusses force changes at hinge joints and columns, respectively analyses the angles of the column and roof beams, and conducts vibration analysis of the columns and balance jack. Section 5 summarizes the conclusions.

\section{METHODOLOGY}

\subsection{Establishment of numerical simulation model of hydraulic support}

The numerical simulation model of hydraulic support is established as shown in Fig. 1, where 1 is the upper beam, 2 is the leg, 3 is the base, 4 is the rear bar, 5 is the front bar, 6 is the shield beam, 7 is the balance jam, and a-c are the panel points. The model height is set to the maximum working height of the hydraulic support. First, material properties of components are determined, including density $\left(7860 \mathrm{~kg} / \mathrm{m}^{3}\right)$, Young's modulus $\left(2.1 \times 10^{11} \mathrm{~Pa}\right)$ and Poisson's ratio $(0.3)$. The column and balance jack of the hydraulic support are replaced equivalently by the spring-damping system. Hinge joints between the roof beam and shield beam, between the shield beam and front and back connecting rods, and between the front and back connecting rods and the base are used by "revolution joints". Friction coefficients in "revolution joints" are set to 0.1. The support base serves as the rack and is locked on the ground by the rigid body and "fixed joints". Finally, the gravitational field is applied perpendicular to the support base.

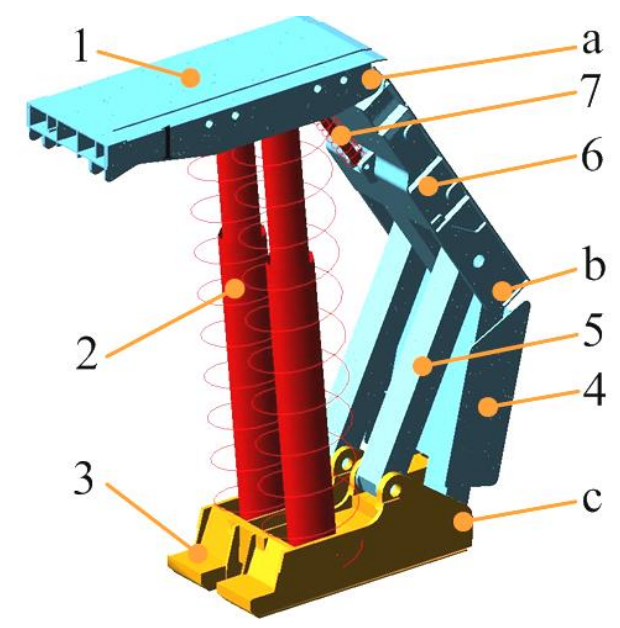

Figure 1: Simulation model of the hydraulic support.

Owing to changes in impact load positions and the effects of small deformation of the support structure on force transmission and force equilibrium, the meshing of roof beam, shield beam, and front and back connecting rods and the related flexibility process are facilitated by Hypermesh software in this study. The rigid body model in Adams software is replaced to form a rigid-flexible coupling model with the rigid base. The flexible meshing of components is shown in Fig. 2. Circles are rigid-connected regions of hinge joints of components, and the corresponding constraints are defined at principal nodes in this region for the convenience of force transmission. 

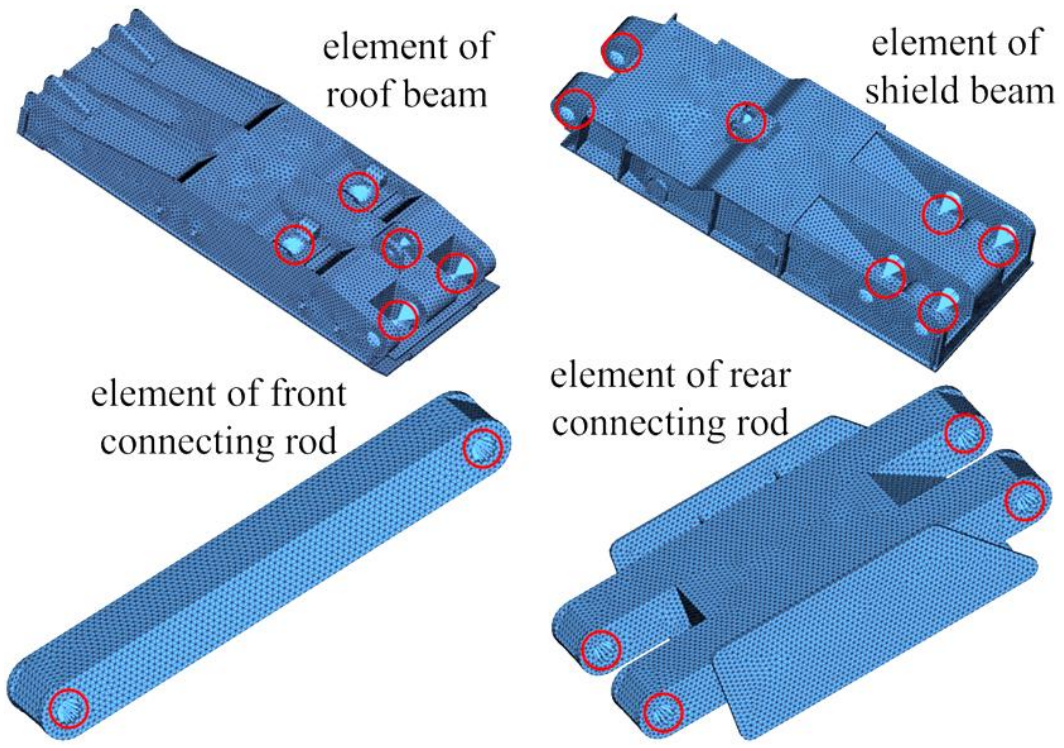

Figure 2: Finite element models of the shield beam.

\subsection{Determination of spring stiffness in the system}

The roof beam of the support bears pressure from the roof, and the emulsion liquid in the column and balance jack cylinder is compressed. Furthermore, support height is decreased and pressure in the cylinder is increased, providing adequate support force to resist roof pressure. Given that simulation tests based on the rigid column model cannot meet compression-induced pressure rises in the hydraulic cylinder, the spring-damping system is replaced by the column and balance jack of the support equivalently in this study, and the compression-induced pressure rise in the hydraulic cylinder is attained by setting reasonable spring stiffness. The hydraulic cylinder parameters are listed in Table I, and the equivalent stiffness calculation [24] is expressed as follows.

$$
K=\frac{A \beta}{L}
$$

where, $K$ is the equivalent stiffness coefficient $(\mathrm{N} / \mathrm{m}), A$ is the active area when the hydraulic cylinder transmits fluid pressure $\left(\mathrm{m}^{2}\right), \beta$ is the bulk modulus of elasticity of hydraulic fluid and $\beta=1.95 \times 10^{3} \mathrm{~K} / \mathrm{MPa}$ for the oil-in-water emulsion, and $L$ is the length of effective liquid column in the hydraulic cylinder $(\mathrm{m})$.

Table I: Main parameters of columns and balance jack.

\begin{tabular}{|l|c|c|c|c|}
\hline \multicolumn{2}{|c|}{ Hydraulic cylinder } & $\begin{array}{c}\text { Diameter of } \\
\text { hydraulic cylinder } \\
(\mathrm{mm})\end{array}$ & $\begin{array}{c}\text { Diameter of } \\
\text { hydraulic bar }(\mathrm{mm})\end{array}$ & $\begin{array}{c}\text { Length of effective } \\
\text { liquid column }(\mathrm{mm})\end{array}$ \\
\hline \multicolumn{2}{|c|}{ Balance jack } & 377 & 320 & 760 \\
\hline \multirow{2}{*}{ Column } & $1^{\text {st }}$ class cylinder & 625 & 530 & 2110 \\
\cline { 2 - 5 } & $2^{\text {nd }}$ class cylinder & 500 & 380 & 2200 \\
\hline
\end{tabular}

Eq. (1) indicates that the equivalent stiffness of the balance jack is $K_{1}=2.06 \times 10^{8} \mathrm{~N} / \mathrm{m}$, the equivalent stiffness of the first-class cylinder (upper cylinder) of the column is $K_{2}=1.0 \times 10^{8} \mathrm{~N} / \mathrm{m}$, and the equivalent stiffness of the second-class cylinder (lower cylinder) of the column is $K_{3}=2.04 \times 10^{8} \mathrm{~N} / \mathrm{m}$. Specific settings of the spring-damping system of double flexible columns are determined based on working characteristics in different working stages. When the externally applied load is smaller than the setting load of the support, the column 
length remains the same. Under this circumstance, the setting load is provided by the equivalent spring preload. When the externally applied load is larger than the setting load of the support and smaller than the initial pressure in the second-class cylinder of the column, the first-class cylinder of the column begins to be compressed. At this moment, the overall stiffness of the column is $K_{L}=K_{2}=1.0 \times 10^{8} \mathrm{~N} / \mathrm{m}$. When the externally applied load is larger than the initial pressure in the second-class cylinder of the column, the second-class cylinder of the column begins to be compressed. In this case, the column stiffness is determined by the stiffness after series connection of the first-class and second-class cylinders, as expressed in Eq. (2).

$$
K_{L}=K_{2} \times K_{3} /\left(K_{2}+K_{3}\right)=6.71 \times 10^{7} \mathrm{~N} / \mathrm{m}
$$

According to the working process of the above columns, stiffness documents are programmed externally and then input into ADAMS software to replace equivalent stiffness of the spring-damping system of the column. Thus, settings of the spring-damping system with variable stiffness are attained.

\subsection{Application of active external load and impact load}

With the maximum working resistance of the hydraulic support at $21000 \mathrm{kN}$, the working resistance in this simulation analysis is determined as $14000 \mathrm{kN}$, which is mainly attained by two active externally loads ( $F_{1}$ and $F_{2}, 7000 \mathrm{kN}$ each). The impact force is applied above the upper needling of two columns downward and perpendicular to the roof beam. The force starts to be applied after the hydraulic support is stabilized under $14000 \mathrm{kN}$. To discuss the impact trend of the roof beam and shield beam on hydraulic support after the impact, the normal impact forces on the roof beam $\left(F_{D i}\right)$ and on the shield beam $\left(F_{Y i}\right)$ were both determined as $3000 \mathrm{kN}$. These forces are applied at the symmetric centre (sym-centre) of the beams.
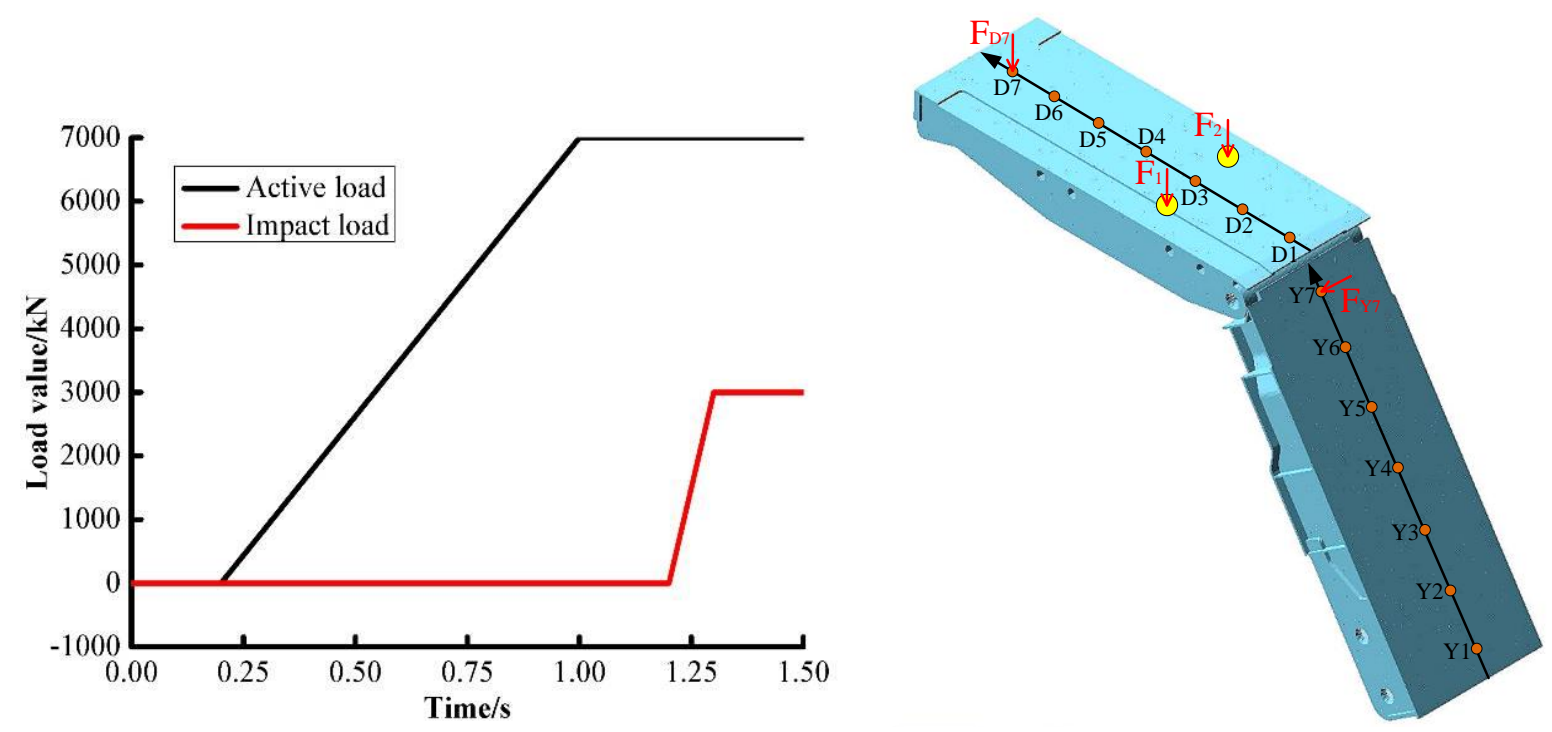

Figure 3: Load curves of active load and impact load. Figure 4: Specific application positions of load.

Specific curves of active external load and impact load are shown in Fig. 3. The active external load is controlled by step (time, $0.2,0,1,7000$ ) and the impact load is controlled by step (time, 1.2, 0, 1.3, 3000). Specific application positions of loads are shown in Fig. 4. Seven loading positions (D1 D7) are collected in the sym-centre of the roof beam at an equivalent interval, and another seven positions (Y1 Y7) are collected in the sym-centre of the shield beam at an equivalent interval. Impact load is applied successively based on different analysis working conditions. When the hydraulic support is in the initial stable state 
during normal operation, it fails to control all impact loads. When only the roof beam is impacted, $F_{\mathrm{D} 1} \sim F_{\mathrm{D} 7}$ are activated successively. When both roof beam and shield beam are impacted, $F_{\mathrm{D} 1}$ and $F_{\mathrm{Y} 1}$ are activated simultaneously in the first group. After the analysis ends, $F_{\mathrm{Y} 1}$ is failed and $F_{\mathrm{Y} 2}$ is activated. In this case, $F_{\mathrm{D} 1}$ and $F_{\mathrm{Y} 2}$ are activated simultaneously for the second group of analysis. This process repeats until $F_{\mathrm{D} 7}$ and $F_{\mathrm{Y} 7}$ are activated simultaneously as the $49^{\text {th }}$ group.

\section{RESULT ANALYSIS AND DISCUSSION}

For a contrastive analysis of simulation results, simulation data related to force and angle are processed based on the surface format in one space. D1 D7 and Y1 Y7 are used as coordinates of the XOY reference plane to measure angles and forces, both of which are used as the height coordinates. D1 D7 represent the length of the roof beam and Y1 $\sim$ Y7 are the lengths of the shield beam. The light green surface 1 denotes the initial stable forces at the hinge joints of the hydraulic support and angle of the roof beam under the working resistance of $14000 \mathrm{kN}$. It is a plane and the numerical values remain constant as $D_{i}$ and $Y_{i}$. The cinereous surface 2 denotes the response values of forces and angles at different positions of the hydraulic support when only the roof beam is impacted. The numerical values only change with $\mathrm{D}_{i}$. The light blue surface 3 denotes the response values of forces and angles at different positions of the hydraulic support when both roof beam and shield beam are impacted simultaneously. Numerical values change with $\mathrm{D}_{i}$ and $\mathrm{Y}_{i}$. Variation trends of the hydraulic support under different impact conditions can be gained by comparing three surfaces.

\subsection{Force analysis at hinge joints}

Hinge joints of the hydraulic support are key points for component connection and force transmission. Roof pressure is undertaken by the roof beam first and then transmitted to the base via the columns and hinge joints. Roof pressure is transmitted to the baseboard from the base until the entire support system reaches balance. Observing changes of forces at hinge points is important in studying such force transfer process. In this study, data about force changes at three hinge points after the impact load are processed, as shown in Figs. 5-7.

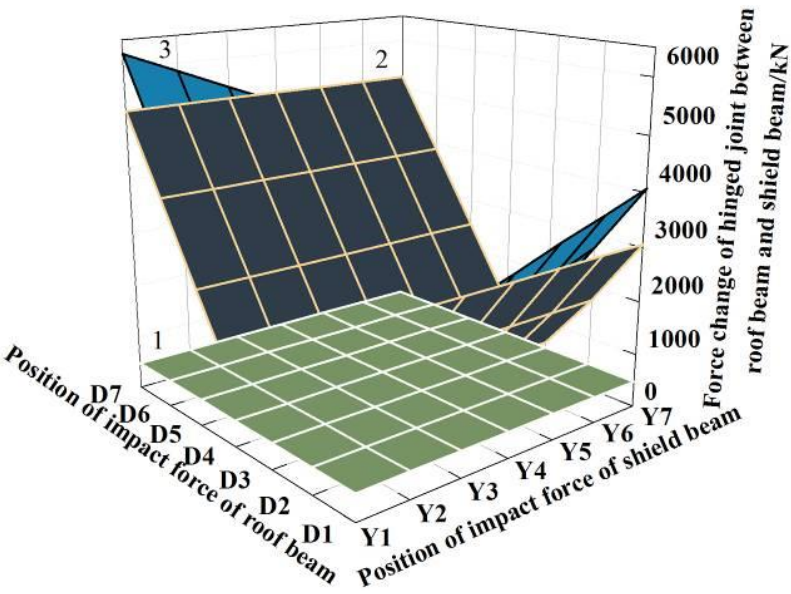

Figure 5: Force changes at the hinged joint between roof beam and shield beam.

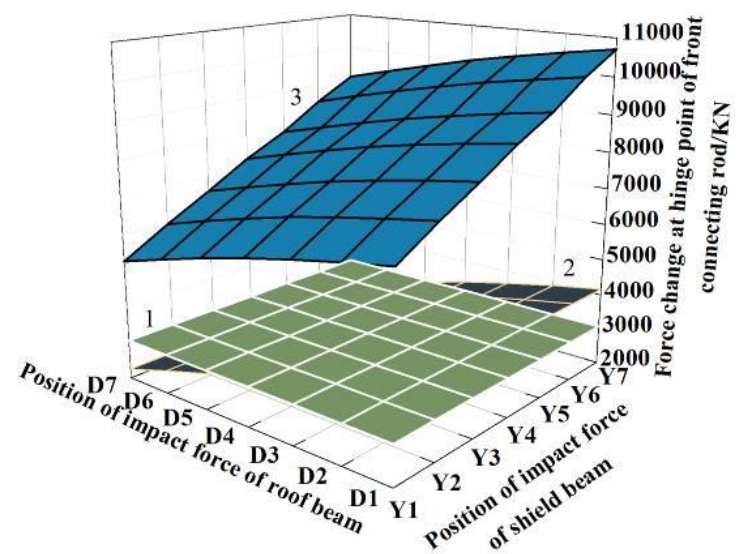

Figure 6: Force changes at the hinge point of the front connecting rod.

Force changes at the hinge point between the roof beam and shield beam are shown in Fig. 5. After the roof beam suffers from impact load, force at this hinge point increases to a certain extent when no impact occurs on the hydraulic support. Viewed from the length of the 
roof beam, such an increase decreases first and then increases. The maximum growth is caused by the front impact force of the roof beam, and the minimum growth is attributed to the impact force close to the needling of the main support. When both roof beam and shield beam are affected, force at this hinge point indicates a consistent variation trend with the case when only the roof beam is affected. Viewed from the length of the shield beam, force at this hinge point increases gradually upon the collaborative action of the impact force from the rear end of the roof beam to the place close to needling and the impact force from the shield beam. However, the force decreases gradually upon the collaborative action of the impact force from the front end of the roof beam and the impact force on the shield beam.

Force changes at the hinge point of the front connecting rod are shown in Fig. 6. After the roof beam is affected, force at this hinge point presents growth and decreases before the impact. Viewed from the length of the roof beam, force at this hinge point decreases continuously. When both roof beam and caving beam are affected, force at this hinge point increases sharply compared with the case when only the roof beam is affected. Such growth decreases when gradually viewed from the length of the roof beam, but it increases when gradually viewed from the length of the shield beam. The maximum growth is caused by the impact force at the rear end of the roof beam and the front end of the shield beam, whereas the minimum growth is caused by the impact force at the front end of the roof beam and rear end of the shield beam.

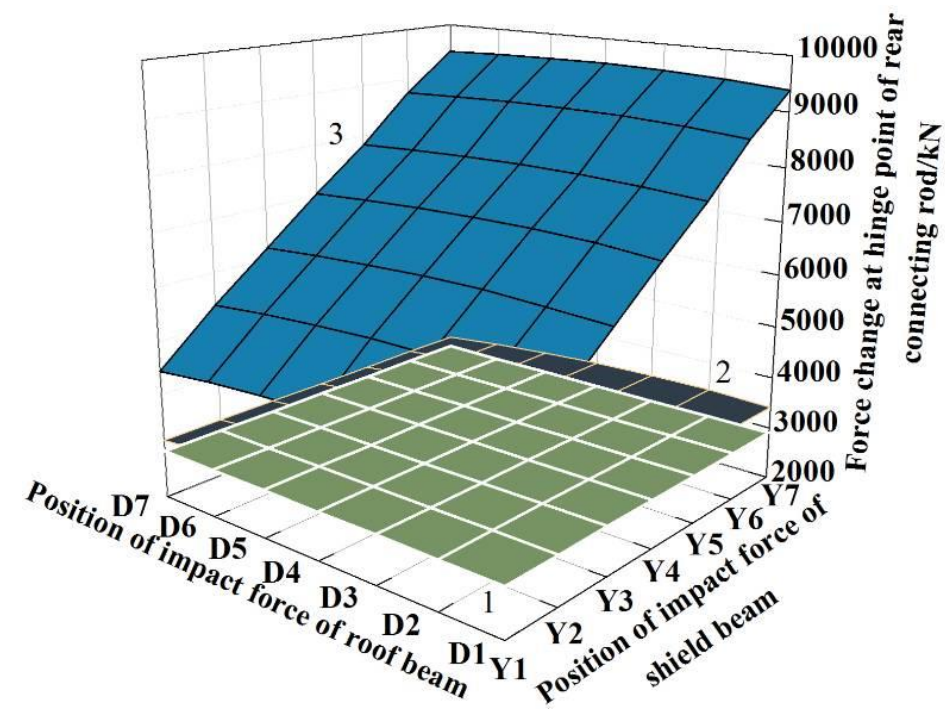

Figure 7: Force change at the hinge point of the rear connecting rod.

Force changes at the hinge point of the back connecting rod are shown in Fig. 7. After the impact load reaches the roof beam of the hydraulic support, force at this hinge point increases slightly compared with before. Viewed from the length of the roof beam, this growth decelerates to a certain extent. When both roof beam and shield beam are affected simultaneously, force at this hinge point is significantly higher than the case when only the roof beam is affected. This growth changes slightly when viewed from the length of the roof beam but increases continuously when viewed from the length of the shield beam. The maximum growth is caused by the impact force on the roof beam and front end of the shield beam, whereas the minimum growth is attributed to the impact force on the roof beam and rear end of the shield beam.

\subsection{Force analysis at columns}

Columns are located between roof beams and base and are crucial in controlling bearing capacity, force transmission, and pose of the support. In studies on support stiffness, many 
scholars either view stiffness of support as directly equivalent to the stiffness of the column or use stiffness of columns as the principal part of the stiffness of the support. Therefore, columns are the most central bearing component of the support. Analysing stress changes of columns with specific bearing capacities of support is critical to studying the overall force transmission of supports. On this basis, a statistical analysis of stress changes of columns after the application of impact force was conducted, in which stress changes on single columns were obtained, as shown in Fig. 8.

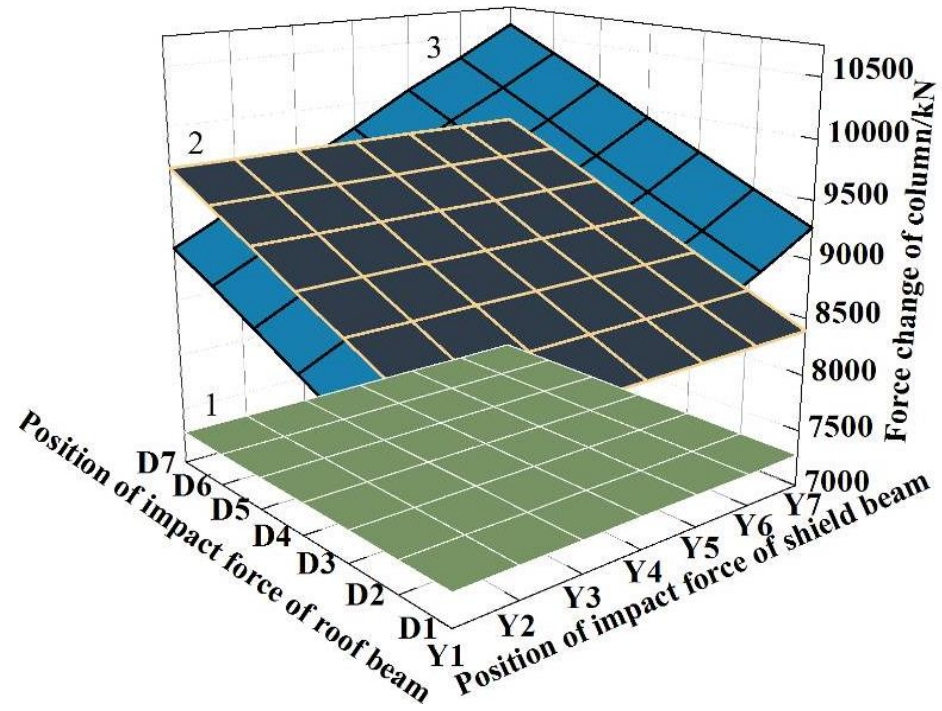

Figure 8: Force changes of column.

As illustrated in Fig. 8, after the roof beam is affected, the force at columns increases to a certain extent compared with that before the impact. Viewed from the length of the roof beam, such growth accelerates continuously. When both roof beam and shield beam are affected, force at columns indicates growth and reduction compared to that when only the roof beam is affected. The impact load on the second half segment of the shield beam decreases the force of columns, and the impact load on the first half segment increases the force of columns. Similar variation trend along the length of the roof beam is observed. However, force at columns decreases continuously from the length of the shield beam. The minimum force is attributed to the impact forces at the rear ends of the roof beam and caving beam, but the maximum force is attributed to the impact forces at the front ends of the roof beam and caving beam.

\subsection{Analysis on angles of column and roof beam}

Stability of hydraulic support under the shaft is sensitive to many factors, such as load changes, support pose changes and actual geological conditions. The specific pose of the hydraulic support can be reflected indirectly by angles of columns and roof beam. Analysing angle changes of columns and roof beams after the application of impact load is important in studying stable pose control of the support.

Angle changes of columns and roof beams after impact are shown in Figs. 9 and 10, respectively. Angle of column refers to the included angle between the centre line of columns and the normal under surface of the base, and angle of roof beam refers to the included angle between the top surface of roof beam before and after impact (positive means the roof beam points upward, and negative means the roof beam points downward). 


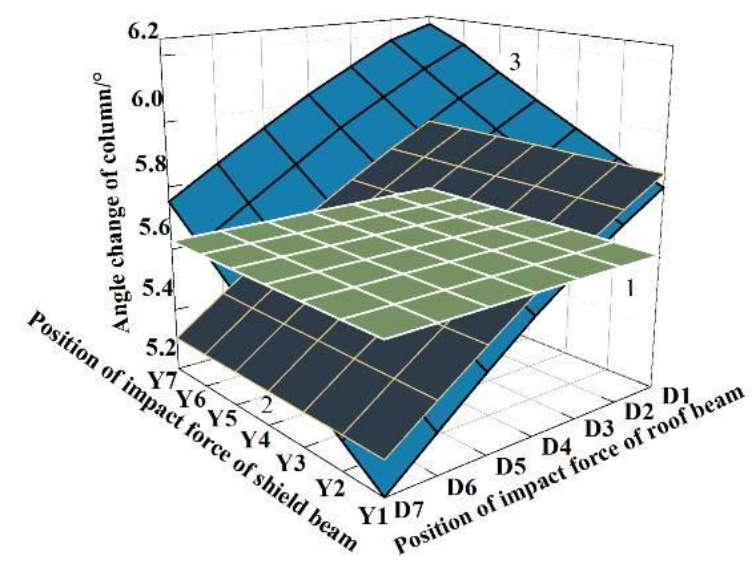

Figure 9: Angle changes of column.

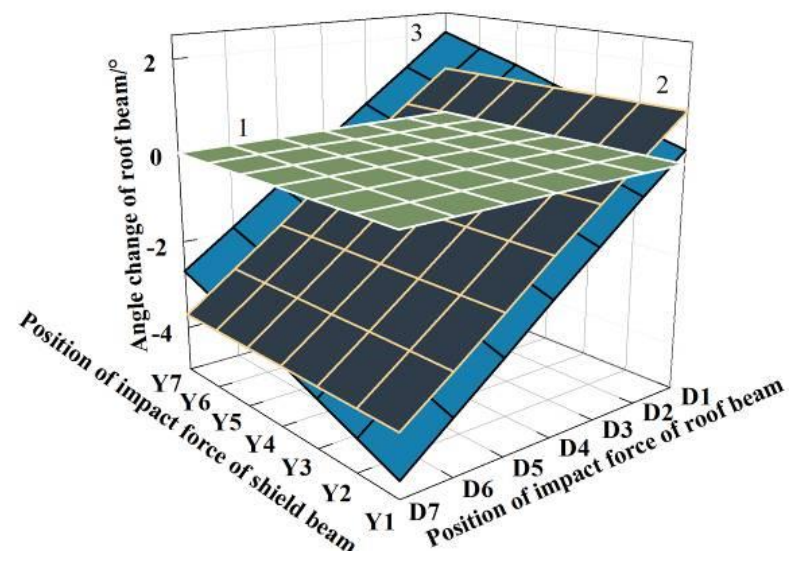

Figure 10: Angle changes of roof beam.

Angle changes of the column are shown in Fig. 9. After impact load is applied to the roof beam, the angle of columns indicates growth and reduction compared with prior values. The angle of columns decreases because of impact force at the first half segment of the roof beam but increases because of impact force at the second half segment of the roof beam. It then decreases continuously from the length of the roof beam. When impact load is applied to the roof and shield beams, the angle of columns indicates growth and reduction. Impact force at the rear end of the shield beam results in a reduction, whereas impact force at the remainder of the shield beam results in growth. Consistent variation law of angle of columns is observed along the length of the roof beam. However, the angle increases gradually along the length of the shield beam. The minimum angle is formed by impact force at the front end of the roof beam and the rear end of the shield beam. The maximum angle is caused by impact force at the rear end of the upper beam and the front end of the shield beam.

Angle changes of the roof beam are shown in Fig. 10. After impact load is applied to the roof beam, the angle of the roof beam indicates growth and reduction compared with prior values. Its growth is caused by impact force from the rear end of the roof beam to the place close to the needling, and its reduction is caused by the impact force from the place close to the needling and the front end of the roof beam. The angle decreases gradually along the length of the roof beam. After impact load is applied to both roof beam and shield beam, the angle of the roof beam indicates both growth and reduction compared with that when impact load is applied to the roof beam. The reduction is caused by the impact force of the second half segment of the shield beam, and the increase is caused by the impact force of the first half segment. Consistent variation trend is observed along the length of the roof beam, but the angle of the roof beam increases continuously along the length of the caving beam. The minimum angle is caused by impact force at the front end of the roof beam and the rear end of the shield beam. The maximum angle is caused by the impact of the rear end of the upper and front ends of the shield beam.

\subsection{Vibration analysis of columns and balance jack}

Hydraulic support not only has one overall stiffness characteristic (centred at columns) but also overall damping characteristics. Damping characteristics are related to the material characteristics of components, valve features in oil channels in the support cylinder (especially responses of safety valves in columns and balance jack), and emulsion compression. However, damping of the column and balance jack hydraulic control system remains the key factor. Under normal conditions, load on the support changes slightly and the support is easy to stabilize, thereby quickly reaching the equilibrium state. Nevertheless, the action time of impact load is short and force changes significantly. Under such suddenly 
changed loads, an equilibrium and stable process is needed for the support to achieve support stability. Response time to this equilibrium stability varies upon strength of impact load, action time, and action positions. In this study, stabilization process of the hydraulic support under impact load is predicted by analysing vibrations of the columns and balance jack. Changes in piston position in the column when the impact load is applied on the roof beam are shown in Fig. 11 (LD1 LD7 are loading positions D1 D7 of impact load on the roof beam). Changes of piston position in the balance jack when the impact load is applied on the roof beam are shown in Fig. 12 (PD1 PD7 are loading positions D1 D7 of impact load on the roof beam).

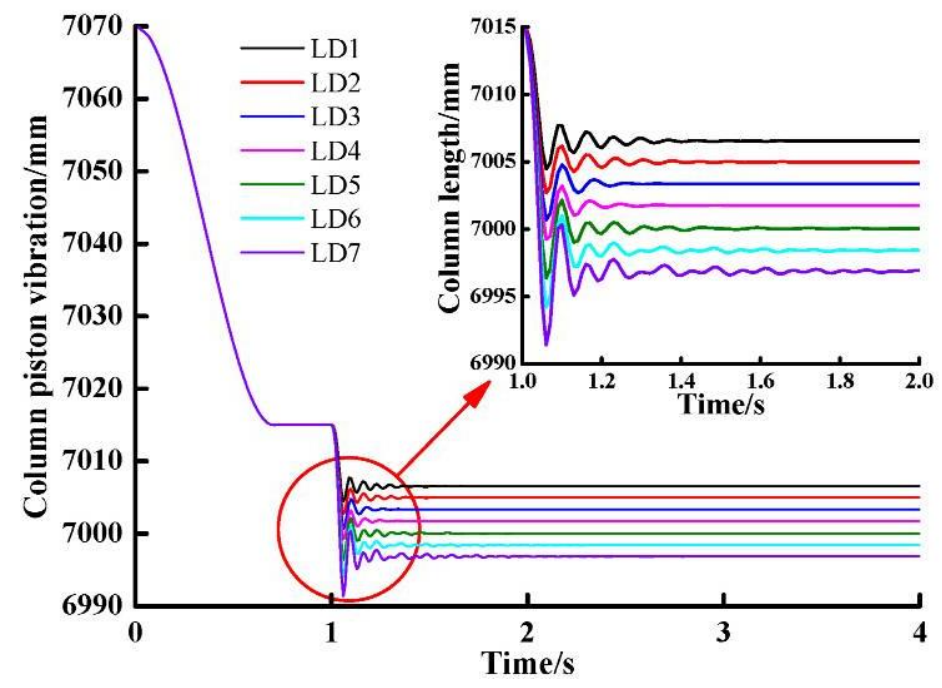

Figure 11: Vibrations of column piston.

Fig. 11 indicates that time for stabilization of the piston position in the column decreases first and then increases when the impact load is applied from the rear end of the roof beam to the front end. When the impact load is applied above the needling, a short time is needed to stabilize piston position in the column. When the impact load is applied to the front end of the roof beam, a long time is needed to stabilize piston position in the column.

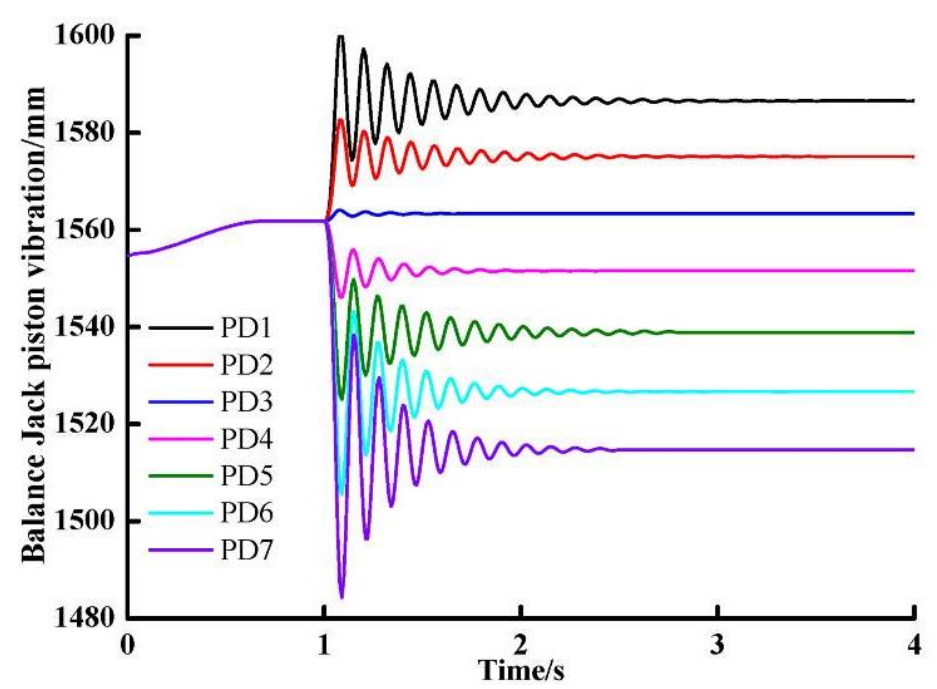

Figure 12: Vibrations of balance jack piston.

In Fig. 12, time for stabilization of piston position in the balance jack decreases first, then increases, and finally decreases when the impact load is applied from the rear end of the roof beam to the front end. When the impact load is applied above the needling of the roof beam, a 
short time is needed to stabilize piston position in the balance jack. When the impact load is applied on the front end of roof beam, a long time is needed to stabilize piston position in the balance jack.

\section{CONCLUSION}

To determine the dynamic responses of hydraulic support under dual impacts from its roof and shield beams, a simulation model of the support was established, and the column and balance jack were substituted using a spring-damper system. Pose analysis was performed and dynamic responses of the support were obtained. Conclusions are drawn as follows.

(1) The force at the hinge point between the roof beam and shield beam and the force at the column comprise the strongest response to single impact force when impact load is only applied to the roof beam. However, when impact load is applied to the roof beam and shield beam, force at the hinge joint between the front and back connecting rods responds primarily to dual impact force.

(2) Owing to the impact load at the rear end of the roof beam, the angle of column increases $\left(0.67^{\circ}\right)$ and the roof beam points upward $\left(6.50^{\circ}\right)$, when impact load is only applied on the roof beam. However, when impact load is applied to the front end of the roof beam, the angle of column decreases and the column points downward.

(3) When impact load is also applied to the shield beam, impact force at front end of the shield beam increases the angle of column $\left(0.97^{\circ}\right)$, accompanied by a larger rising angle and a smaller bow angle of the roof beam $\left(7.20^{\circ}\right)$. The impact force at rear end of shield beam causes a smaller column angle, accompanied by a smaller rising angle and larger bow angle.

This study is helpful for achieving stability control and structural design of hydraulic support. However, given that the working conditions of hydraulic support are extremely complex in mines, only two typical impact loads are used to perform a pose and dynamic analysis. In future research, the dynamic response of the hydraulic support under three or more resultant impact loads will be considered.

\section{ACKNOWLEDGEMENT}

This work was supported by the National Natural Science Fund of China (Grant No. U1361127) and National Key Research and Development Program of China (Grant No. 2016YFC0600907).

\section{REFERENCES}

[1] Prebil, I.; Krašna, S.; Ciglarič, I. (2002). Synthesis of four-bar mechanism in a hydraulic support using a global optimization algorithm, Structural and Multidisciplinary Optimization, Vol. 24, No. 3, 246-251, doi:10.1007/s00158-002-0234-y

[2] Zhang, Q.; Zhang, J.-X.; Tai, Y.; Fang, K.; Yin, W. (2015). Horizontal roof gap of backfill hydraulic support, Journal of Central South University, Vol. 22, No. 9, 3544-3555, doi:10.1007/s11771-015-2894-y

[3] Witek, M.; Prusek, S. (2016). Numerical calculations of shield support stress based on laboratory test results, Computers and Geotechnics, Vol. 72, 74-88, doi:10.1016/j.compgeo.2015.11.007

[4] Wang, Z. B.; Zhao, L. L.; Li, S. B.; Ni, W. F. (2009). Optimization design for hydraulic-support of standing shield, Journal of Chongqing University, Vol. 32, No. 9, 1037-1042

[5] Singh, G. S. P.; Singh, U. K. (2010). Prediction of caving behavior of strata and optimum rating of hydraulic powered support for longwall workings, International Journal of Rock Mechanics and Mining Sciences, Vol. 47, No. 1, 1-16 doi:10.1016/j.ijrmms.2009.09.001

[6] Pytlik, A. (2016). Process characteristics of hydraulic legs equipped with safety valves at dynamic load caused by a mining tremor, Archives of Mining Sciences, Vol. 60, No. 2, 595-612, doi: $\underline{10.1515 / \mathrm{amsc}-2015-0039}$ 
[7] Jiao, L. D.; Lian, Z. S. (2010). Dynamic characteristics simulation of large flow relief valve in hydraulic support, Mechanical Engineering and Automation, Vol. 13, No. 5, 4-6

[8] Frith Russell, C. (2015). A holistic examination of the load rating design of longwall shields after more than half a century of mechanised longwall mining, International Journal of Mining Science and Technology, Vol. 25, No. 5, 687-706, doi:10.1016/j.ijmst.2015.07.001

[9] Wan, L. R.; Wu, X. W.; Wang, C. L.; Zhang, X. (2010). Mechanical-hydraulic integration modeling and simulation of hydraulic support, 2010 International Conference on Computer Application and System Modeling (ICCASM), Vol. 5, 69-72, doi:10.1109/ICCASM.2010.5619349

[10] Verma, A. K.; Deb, D. (2013). Numerical analysis of an interaction between hydraulic-powered support and surrounding rock strata, International Journal of Geomechanics, Vol. 13, No. 2, 181192, doi:10.1061/(ASCE)GM.1943-5622.0000190

[11] Boutrid, A.; Djouamaa, M. C.; Chettibi, M.; Bouhedja, A.; Talhi, K. (2016). Design of a model powered support system in Kenadsa mine (Algeria), Journal of Mining Science, Vol. 52, No. 1, 78-86, doi:10.1134/S1062739116010150

[12] Singh, G. S. P.; Singh, U. K. (2009). A numerical modeling approach for assessment of progressive caving of strata and performance of hydraulic powered support in longwall workings, Computers and Geotechnics, Vol. 36, No. 7, 1142-1156, doi:10.1016/j.compgeo.2009.05.001

[13] Oblak, M.; Harl, B.; Butinar, B. (2000). Optimal design of hydraulic support, Structural and Multidisciplinary Optimization, Vol. 20, No. 1, 76-82, doi:10.1007/s001580050138

[14] Wang, G. F.; Pang, Y. H.; Li, M. Z.; Ma, Y.; Liu, X. H. (2017). Hydraulic support and coal wall coupling relationship in ultra large height mining face, Journal of China Coal Society, Vol. 42, No. 2, 518-526, doi:10.13225/j.cnki.jccs.2016.0699

[15] Wang, X.; Yang, Z.; Feng, J.; Liu, H. (2013). Stress analysis and stability analysis on doublytelescopic prop of hydraulic support, Engineering Failure Analysis, Vol. 32, 274-282, doi:10.1016/j.engfailanal.2013.04.006

[16] Ren, H. W. (2011). Study on rational working height and shield beam structure of high cutting hydraulic powered support, Coal Science and Technology, Vol. 39, No. 4, 89-93, doi:10.13199/j.cst.2011.04.94.renhw.024

[17] Zhao, X. H.; Li, F. Y.; Liu, Y.; Fan, Y. J. (2015). Fatigue behavior of a box-type welded structure of hydraulic support used in coal mine, Materials, Vol. 8, No. 10, 6609-6622, doi: $10.3390 / \mathrm{ma} 8105325$

[18] Liang, L. C.; Tian, J. J.; Zheng, H.; Jiao, S. J. (2015). A study on force transmission in a hydraulic support under impact loading on its canopy beam, Journal of China Coal Society, Vol. 40, No. 11, 2522-2527, doi:10.13225/j.cnki.jccs.2015.7021

[19] Yu, L.; Yan, S.-H.; Yu, H.-Y.; Zhang, Z. (2011). Studying of dynamic bear characteristics and adaptability of support in top coal caving with great mining height, Procedia Engineering, Vol. 26, 640-646, doi:10.1016/j.proeng.2011.11.2217

[20] Xuan, B. T.; Nur, H.; Hideki, Y. (2012). Modeling of dynamic friction behaviors of hydraulic cylinders, Mechatronics, Vol. 22, No. 1, 65-75, doi:10.1016/j.mechatronics.2011.11.009

[21] Boaventura, T.; Semini, C.; Buchli, J.; Frigerio, M.; Focchi, M.; Caldwell, D. G. (2012). Dynamic torque control of a hydraulic quadruped robot, 2012 IEEE International Conference on Robotics and Automation (ICRA), 1889-1894, doi:10.1109/ICRA.2012.6224628

[22] Wang, L. H.; Wu, B.; Du, R. S.; Yang, S. Z. (2007). Nonlinear dynamic characteristics of moving hydraulic cylinder, Chinese Journal of Mechanical Engineering, Vol. 43, No. 12, 12-19

[23] Jiang, G. Y.; Wang, Y. Q.; Yan, X. C. (2008). Mathematics modeling and simulation analysis of dynamic characteristics for hydraulic cylinder controlled by servo-valve, Journal of Sichuan University (Engineering Science Edition), Vol. 40, No. 5, 195-198

[24] Zhang, Z. J.; Gu, K. Q.; Zhang, X. L. (2016). Finite element method to calculate hydraulic cylinder stiffness, Journal of Gun Launch \& Control, Vol. 37, No. 1, 55-58, doi:10.19323/j.issn.1673-6524.2016.01.012 